https://helda.helsinki.fi

\title{
Analytical and methodological considerations for the use of social categories in identity research
}

\section{Benjamin, Saija}

2016

Benjamin , S \& Kuusisto , A 2016 , ' Analytical and methodological considerations for the use of social categories in identity research ' , International Journal of Bias, Identity and

Diversities in Education , vol. 1, no. 1, pp. 13-27 . https://doi.org/10.4018/IJBIDE.2016010102

http://hdl.handle.net/10138/329699

https://doi.org/10.4018/IJBIDE.2016010102

Downloaded from Helda, University of Helsinki institutional repository.

This is an electronic reprint of the original article.

This reprint may differ from the original in pagination and typographic detail.

Please cite the original version. 


\title{
Analytical and Methodological Considerations for the Use of Social Categories in Identity Research
}

Saija Benjamin, University of Helsinki, Helsinki, Finland

Arniika Kuusisto, University of Helsinki, Helsinki, Finland

\begin{abstract}
This paper examines the limitations of measuring identities as based on pre-selected categories, such as 'immigrant' or 'Third Culture Kid', within which the individuals are placed according to particular criteria. Simplified, etic categories fail to mirror the complex identifications of the contemporary individual and strengthen essentialism related to ethnicities, cultures and religions. This paper discusses the problematic related to categorization at both analytical and methodological levels. The need for critical reflection on the use of social categories to portray identities is highlighted in general. The adequacy of surveys to measure and examine identities is questioned in particular. This paper illustrates the need to approach identities from emic-etic perspectives and multiple angles in order to grasp a more multilayered view into the complex nature of identity.
\end{abstract}

\section{KEYWORDS}

Emic, Essentialism, Etic, Identity, Identity Measures, Power, Social Categories, Stereotypes, Survey Method, Terminology, Youth

\section{INTRODUCTION}

The single story creates stereotypes, and the problem with stereotypes is not that they are untrue, but that they are incomplete. They make one story become the only story. (Adichie, 2009)

Social categories have a long history within social sciences (Wiley \& Revenson, 2012). Human beings think through categories, and as long as humans have existed, different categories have existed. People use categories like black, white, French, Christian, gay, or Hispano - in order to comprehend the social environment around them and to position themselves within the complex network of social settings in everyday life. This positioning is a two-dimensional process, which happens both by self- 
categorization, continuous re-categorization and by external labeling. Deaux (2012) talks about 'actor' and 'observer' categories respectively. However, although an individual may voluntarily identify with the social category s/he is placed in externally, for example being a 'Muslim', it is problematic to think that there is an isomorphism between the 'actor' and 'observer' categories. It is of essence to understand that despite the same category name, different processes, understandings and power structures are involved (Deaux, 2012).

In order to make this distinction clearer, this paper proposes going back to the concepts of 'etic' and 'emic' coined by linguistic anthropologist Kenneth Pike (1954), with etic referring to objective or 'observer' accounts, and emic referring to subjective or 'actor' accounts. Participant-generated, emic research aims to understand original phenomenon in its own context and to generate descriptions with criteria chosen from within the system (Berry, 1989, p. 722). Identity categories are often operated within researcher-generated, etic research. In this context, categories are typically used to produce an overall view of how typical particular identifications are among a large number of people in a particular society or across countries, or to explore differences between social categories, like ethnic groups, in outcomes such as health (Pearson \& Geronimo, 2011) or educational inequality (Stevens, 2007), for example.

However, social categories are mere social constructs embedded in specific times and contexts (Wiley \& Revenson, 2012). As societies are undergoing rapid demographic changes and the 'mixedness' of individuals is increasing, it is timely to reevaluate the use of social categories in public discourses in general and in research in particular. First of all, what is the gain of operating with these categories while at the same time their boundaries become more and more blurred in societies (De Vidas \& Hoffmann, 2012)? When mobility and dislocation are consistent features of everyday life for more and more people (today, more than 230 million people live outside their birth country; UN 2013), who can be categorized, for example, as 'immigrant' and across how many generations does this category apply? Second, research operating with pre-determined social categories may only reflect the researcher's often outsider, etic understanding of the phenomena in question. It is rooted in subjectively construed presuppositions and stereotypes about the characteristics of each group, which consequently become framed in the categories (Prentice \& Miller, 2007). This leads us to the question of whose 'truth' is being measured with social categories and what kind of knowledge they can produce? Can one really examine and understand people's multiple identifications through the use of clear-cut, generalizing social categories in research?

In this regard, this article critically reviews, through examples from previous identity studies, the inclination and possible problematic of many traditional research designs to present and measure identity based on pre-selected categories, such as a particular ethnic or religious identity, within which the individuals are positioned by someone who has the authority and power to do this - typically the researcher. As identities that for long defined the social and cultural world of modern societies (i.e. ethnicity, race, class, nationality etc.) have been weakening (Bauman, 1996) and the understanding of identity has shifted during the past few decades, the research methods and tools to examine it need to be re-thought accordingly. This paper discusses the use of social categories at two different levels. First, at analytical level considering the compatibility of social categories with the post-modern conceptions of identity, the power differentials and political agendas involved, and the consequences of the use of social categories at individual and societal levels. Second, at methodological level considering the problems embedded in research designs, measures and terminology used to create social categories to describe individual identities. What is proposed here is moving away from narrow category-based thinking towards a more multifaceted understanding of individual identifications and more fine-tuned research approaches and terminology that better reflect the true diversity within the societies, and the multiple identities of the individuals inhabiting them. Research acknowledging a more sensitive perspective to identities as well as emic, actor-generated approaches understands identity construction and group identification as processes that are unique to each individual, despite of their 'official' belongings. 


\section{Identity as a Strong or Weak Conception}

Identity is a complex notion, which lends itself to numerous definitions. In this article, Brubaker and Cooper's (2000, p. 6-8) identification of the key uses of the concept of identity is utilized:

Identity can be used (1) to underscore the manner in which action-individual or collective-may be governed by particularistic self-understandings rather than by putatively universal self-interest, (2) to denote fundamental and consequential sameness among a group of members of a category. Identity can also be understood (3) as a core aspect of collective or individual 'selfhood', as something deep, basic and foundational in human beings that is to be valued, cultivated, supported, recognized and preserved, or (4) as processual, interactive, collective self-understanding, solidarity or groupness that can make collective action possible. Identity can also be understood, especially in the light of post-modernism and post-structuralism, (5) as the unstable, multiple, fluctuating and fragmented nature of the contemporary 'self'.

The way in which 'identity' is framed in different studies is based on the researcher's ontological and epistemological suppositions on the nature of identity and its measurability. Researchers from different fields have distinctive angles to viewing and studying identities. Referring to the aforementioned definitions, Brubaker and Cooper (2010) talk about strong and weak understandings of identity that are used in different discourses and for different purposes. Strong conceptions of identity ( 2 and 3 ) refer to the traditional meaning of the term and emphasize the sameness over time and across persons (Brubaker \& Cooper, 2000, p. 10). Research, that deals with identities based on broad social categories, such as ethnic identity (Juang \& Syed, 2010; Whitehead, 2009), cultural identity (Otcu, 2010) or religious and national identity (Verkuyten et al., 2012) usually shares strong conceptions of identity, as certain sameness and mutually shared conceptions are assumed across the individuals within a social category (cf. Benjamin \& Dervin, 2015 on essentializing Third Culture Kids). These studies continue to contribute to the literature on ethnicity and nationalism as well in research as in political agendas. Weak understandings of identity (4 and 5), in turn, refer to the conceptions of identity favored in theoretical discussions over the recent years that reject notions of basic sameness (Sen, 2009; Brubaker \& Cooper, 2000). In the post-modern light and in this article, identity is not viewed as 'a coherent entity' or 'fundamental sameness', but as (inter)subjective, unique, constantly changing (Dervin, 2011; Abdallah-Pretceille, 2006) and deeply contextual, therefore corresponding to the weak understandings of identity. In this respect, it becomes problematic to examine individual identifications with the traditional measures and/or assign individuals into any static identity categories. The following sections discuss the problematic related to the use of identity categories in research in general and with youth in particular.

\section{ANALYTICAL CONSIDERATIONS RELATED TO IDENTITY MEASURES}

\section{Self-definition does not occur in a vacuum, but in a world already defined. (Friedman, 1992)}

Researchers from different fields of study approach identities from different angles. The choice of method and tools advocates each researcher's assumptions about the nature of identity. For analytical reasons, it is necessary to understand the distinction between identity as independent and dependent variable. Studies, in which identity is used as an independent variable typically assume that it can change or affect the value or level of a dependent variable (i.e. ethnic identity is the cause of $x$ ). Wherever identity is used as an independent variable, it should be recognized that the acquired knowledge on the given 'identity' is limited and remains, at best, at the surface level. However, when identity is used as a dependent variable, as the object of research and measured by the researcher (i.e. ethnic identities of the immigrant youth in Finland), the use of certain concepts or pre-defined 
categories becomes more problematic. Research on 'identities', especially when carried out by means of a quantitative measure, requires special attention and sensitivity regarding power differentials, language, and translation. In particular these have to be considered if the respondents are young (Lagström et al., 2010; Thomson, 2008), of immigrant background or otherwise vulnerable, or when the researcher is not present in the act of data production in order to open the meaning of the concepts (Kuusisto, 2005, 2011; see also Ogan et al., 2013 and Rantala \& Kuusisto, 2013). These aspects and the problematic related to viewing identity as a dependent variable are discussed in the following sections.

\section{Categories and Power}

Power is the ability not just to tell the story of another person, but to make it the definitive story of that person. (Adichie, 2009)

Social categories always carry meanings focused on issues of power and status, which, to an extent, define the social location of its members in terms of dominance or marginality (Deaux \& Martin, 2003, p. 106). Nation-states remain powerful 'identifiers', because they have the 'material and symbolic resources to impose the categories --- with which bureaucrats, judges, teachers, and doctors must work and to which non-state actors must refer' (Brubaker \& Cooper, 2000, p. 16, see also Lentin, 2013; Starr, 1992). But also scholars contribute to the making of categories. Research creates common sense social categories (i.e. Latino ethnic identity, Muslim identity) and produces public representations and knowledge about them. These 'identities' and the 'information' about them are then legitimated in the public discourses by the 'academic stamp'. For example, studies have indicated 'a natural tendency for in-groups to depreciate out-groups' (i.e. Tajfel, 1981). This idea, 'evidenced by research', has since been sovereignly used as an argument against immigration and multiculturalism (Gillespie et al., 2012, p. 397).

Some of the power is already embedded in the research design: the researcher or the research group formulates the research questions, which more or less determine the kind of information that is sought after and gained, and later on, how this is interpreted. By choosing the methods, the researcher also chooses a certain version of the reality. This version, in turn, puts forth some issues of the study, while excluding some others (Monrad, 2013; Rantala \& Kuusisto, 2013; Puuronen, 2005). Already at this point, the authenticity of the original stories has evidently suffered. In a way, "[r]epresenting the Other is always a process of dominance and control, in which the person represented is reduced to an object' (Krumer-Nevo \& Sidi, 2012, p. 299).

However, this concern applies to both observer-generated 'etic' and actor-generated 'emic' research. Whereas etic, survey-based research runs a risk of displaying a limited image of the individual, the conclusions drawn from an emic interview-based study, for example, are highly dependent on the success of the interaction between the two parties, to 'whom' the participants are actually talking to, what is really being told and how it all is interpreted and put forth by the researcher. Just as easily as etic survey research, emic research approaches can also flatten out identities by importing pre-conceived categories during data collection or analysis. All methods bare weaknesses and limitations, which need to be considered and described when reporting the study in order for the reader to be able to estimate the reliability and validity of the findings.

Evidently, survey measures have their own place and value in research and have considerably generated new knowledge and significant information about various topics related to human groups since several decades (Groves, 2011). They also enable studying patterns of identification, social positions and experiences in large populations (Monrad, 2013, p. 351). However, Monrad points out that in survey-based studies the different voices and points of view of the respondents are actually predetermined by the way the questions are asked, 'since the respondent is called upon to describe herself from a certain perspective and in a certain voice' (2013, p. 353). Therefore, if a survey or 
questionnaire is used as the sole research method and the basis for analysis, the single sided story it tells about the identity of the participants may flatten the true complexity and multidimensionality of each individual and reduce all their possible memberships under one narrow category.

\section{Clear-Cut Categories}

In addition to replicating somewhat outdated demographics, social categories are not geographically or nationally consistent. Social categories, as other 'cultural' realities are always produced in specific socio-historical contexts (Friedman, 1992) and generally accepted as a truthful reflection of humanity, albeit a plethora of identifications is often excluded. For example, most nations recognize only two gender categories - female and male - although a number of their citizens do not identify with any of the two (see Vasey, Parker \& VanderLaan, 2014 on 'Third Gender' recognized i.e. in Samoa). Each nation also has its historically and culturally constructed traditions of distinguishing and characterizing its national ethnic categories. For example, a comparative study on minority ethnic categories ('Indian' and 'Black') in Mexico and Columbia disclosed a significant discrepancy in how members of each group were defined in each country (De Vidas \& Hoffmann, 2012: 1610). Practices of partitioning a population based on clear-cut categories are criticized, not only because they increase incoherence in the society, but also because they demonstrate an inherent 'failure in understanding the nature of social identity and its plural aspects' (Sen, 2009, p. 288). Sen (2009) refers to the experience of his friend, who was categorized as 'Muslim' by the British authorities. In the aftermath of the London bombings in 2005, the British Government demanded for 'all British Muslims to get their act together', to which Sen's friend argued: 'The political leaders of my country want me to act not as a British citizen, nor as a member of the Labour Party, nor as someone active in British civil society, nor as a secularist of Bangladeshi origin, but as a Muslim who must act within what the government has defined as "my community", (Sen, 2009, p. 288).

Categorizing people based on a single, divisive identity is precarious also because people may start to take that identity's supposed demands as 'given' and confound social affiliations with personal sameness. Sen (2009, p. 287) claims that once a social affiliation becomes a part of one's identity, it may be prioritized over other affiliations and become accepted as an integral part of one's 'personhood'. This is a process that Appiah (2005) calls 'identification'; if someone is labeled as an 'L', people start to have beliefs and expectations of him. Gradually this person starts to identify with other 'Ls' and finally, being an 'L' becomes a part of his identity (Appiah, 2005, p. 69; see also Tajfel \& Turner, 1979). Individuals often struggle to separate their personal and social identities, in other words to distinguish their own beliefs from the norms and ideologies of the group they are members of. Sen (2009, p. 287) presumes that the amalgamating of one's identities could be seen to be at the root of the sectarian violence between the Hutus and the Tutsis in Rwanda, for example, from where stems this type of reasoning 'As a Hutu, I could not have done anything else'.

Studies on ethnic, racial and sexual identities are multiple, but at the end, are ethnicity, race and sexual orientation constructs that interest researchers and authorities only? What is the reason for strengthening these as categories, while at the same time the 'mixedness' of the respondents' origins is increasing, and the fluidity of individuals' personal identification is a recognized fact? Obviously, these concepts exist to some extent in mundane discourses, but ethnicity and race seem to be less significant factors especially to the younger generations growing up in the globalized world. Research or other practices that force young people to place themselves in ethnic, cultural, religious or sexual identity categories are not compatible with the realities of the youth - one may not even recognize oneself in any of the given categories. Recent studies on youth identities have showed that 'neighborhood identities' and other youth culture identities related to i.e. music and sports, are more significant to the youth than ethnic or national identifications (Bauer et al., 2013). Even within an identical national identification (i.e. Finnish) the youth may show great variation in terms of values and belief systems (Helve, 2015), which speaks about weakening significance of nationality (although this might not be the case within the youth of younger nations, who have rather recently gained their 
independence). Further, national, ethnic or religious identifications of the youth are context-bound and often so deeply interwoven that defining oneself as member of only one of these becomes problematic (Cetrez, 2011). However, it is possible that the connotations of these identities have changed in one generation - culture, ethnicity and religion may hold different meanings for the youth than for their parents. Traditional cultural and religious affiliations and commitment have decreased amongst youth; lack of identification and spaces of belonging breed a sense of alienation, which can lead to development of so called counter-identities (Taylor, 2009). This development is advanced by the internet, which has enabled new opportunities and spaces for religious and cultural belonging. Numerous extremist groups from the right and the left, both secular and non-secular are lurking on-line, positioned to offer a radical option to vulnerable youngsters who may feel they have no real future at any level of the society. The radicalization of some European youth has caused concern in the media across the continent. It has incited discussion on new kinds of religious or national identifications and even generated novel categories such as 'far right youth' or 'young Jihadists'. Especially the latter has been embraced by European journalists and politicians, who often view the phenomenon from a narrow Western reductionist perspective. Consequently, 'young Jihadists' is yet another category that is problematic and misleading, as by connotation it encompasses a whole religion and all Muslim people (see i.e. Waterman, 2015) and contributes to the imageries of the 'European other'.

\section{METHODOLOGICAL CONSIDERATIONS RELATED TO IDENTITY MEASURES}

\section{Identity Measures: Surveys and Questionnaires}

Questionnaires and surveys have traditionally been a much-used means to examine the different dimensions of identity. Quantitative measures often look at the data from an outsider's etic perspective bringing information about large pools of respondents. On one hand this approach gives the researcher a chance to develop higher-level theories and insights (which the respondents themselves may have no access to), but on the other hand the respondents' own voices and agency are often overlooked in the process. Measures have been developed to examine various aspects of identity (e.g. 'Multigroup Ethnic Identity Measure' Phinney, 1992; 'Racial Identity Measure' Burlew et al., 2000; 'Multidimensional inventory of Black identity' Sellers et al., 1998). Questionnaires and surveys usually aim for high response rates as they can be implemented rather easily and cost-effectively. They can be sent, for example via email or different forums on the internet, to hundreds of individuals within the target group.

Although the prevalence of a particular identification in the society, for example, may still be best measured with a survey approach, the problem is that it may only grasp a relatively narrow perspective to the actual experiences of the research participants. Looking at identity from one angle only crops out the plethora of other aspects therein. In search of more complexity and 'thickness' of data, it is essential to approach individuals from multiple perspectives; thus, complementary tools, such as interviews, need to be utilized in examining identity in order to gain a wider understanding than a mere survey can provide.

\section{Challenges in Survey Terminology}

Studies operating with social categories place individuals into categories according to particular criteria using information obtained from questionnaires or surveys. However, the process may involve many pitfalls. First, filling a survey requires an understanding of the statements and the key concepts used in the measures. For example, gathering information on individuals' attitudes and feelings about their ethnic group with items such as 'I am happy that I am a member of the group I belong to' leave it unclear to the researcher how each respondent interprets 'member'. Can the researcher trust that the respondents can independently make judgments about their personal memberships? Even if an 'official' membership to a group can be gained, for example based on actual citizenship or a membership to a particular religious organization, these 'memberships' may have been determined 
by one's parents in infancy and the resonance to the individual's experience may be weak. Or the experienced belonging may be strong, but the formal membership lacking. Particularly these aspects concern children and young people whose parents already hold a number of different 'cultural', ethnic or religious origins in their family history.

Second, sometimes the statements assume a certain level of abstract reasoning, which has to be pondered especially if the respondents are young. Are the respondents able to comprehend all questions and concepts? A study measured youth's civic engagement according to their ethnic group with statements like 'I understand the issues facing this nation' or 'Individuals are responsible for their own misfortunes' (Anglin et al., 2012). Such survey items can be problematic. In the case that the respondents have not followed politics, for example, their responses on these issues may not have anything to do with their actual understanding of the topic. How can the researchers then use the data obtained from the survey to gather information about certain ethnic groups? (See also McCabe et al., 2013 on the challenges of survey terminology regarding sexual identity.)

As societies are becoming increasingly diverse and the individuals may be holding multiple memberships, the traditional measures examining group identification to religious or national commitments need to be reconsidered. For example, statements like 'I consider myself as a real Muslim' are problematic, as the definitions on 'Muslimness' are 'thick with competing discursive articulations and "objectifications" of Islam [and] there is little space for an unreflective, taken-forgranted identification as a Muslim --- Therefore, "Muslim" is a category towards which one must take a stance; one cannot simply inhabit it in an unreflective manner' (Brubaker, 2013, p. 5). Survey statements may also be too indefinable or too 'large' to grasp. In order to measure immigrant youth's national identification in France, for example, the respondents may typically be asked to assess on five items the extent to which they 'feel French'. However, it should be taken into consideration that France has a population of 66 million with a wide range of religious beliefs, political opinions and languages and of which around eleven per cent are of immigrant origins (INSEE, 2012). So with whom are the respondents supposed to be identifying (or not)? As the above examples illustrate, if the concepts are not well-defined or familiar to the study participants, it is important to ask what kind of information does the data bring? Is the knowledge produced by these studies considered as a true and realist reflection of reality?

\section{Cross-National Translation}

Another challenge in survey based identity studies, especially in cross-cultural research, is that the scales and questionnaires may have to be translated from one language to others in order to match the language of the respondents. Careful reflection on the translation is essential, because similar concepts, when translated, may expose significant differences in their connotations in another language and in different societal contexts. Although professional translators may be experts in languages, they cannot always grasp the sensitive tones of specialized scientific notions. And even if researchers themselves could get particular terms right, they may make linguistic mistakes in their translations, again altering the meaning. Consequently, nationally specific contents may be lost in translation thus making the data, in effect, invalid (see i.e. Shabes et al., 2011).

Many studies start data collection by asking respondents to identify themselves with a category, whether it be language, race or ethnic or religious membership. Let us observe, as an example, the concept of 'ethnicity'. In the US, the term is used on a daily basis by various authorities as well as in the documents, official papers and research. From a young age the US citizens are familiarized with the different categories of 'race and ethnicity' and their place in these categories, as filling in official documents often requires recording one's race or ethnicity as an aspect of personal information. Most European states, in turn, are mainly operating with 'nationality' in terms of self-identification in official papers. As people in Europe are not confronted with the necessity of having to pinpoint their ethnicity in their everyday lives, the terminology related to race and ethnicity may remain indefinite. 
This is one of the many reasons why surveys can never be 'culturally neutral' or simply translatable from one language to another and applicable from one country to another.

In addition, as a result of cross-national, cross-ethnic and cross-faith partnerships, there are more and more individuals with profiles that cross the boundaries of any traditional national or ethnic categories. What becomes their choice of 'official' self-identification? Already today, the fastest growing group of people in the US is those who identify themselves as 'multiracial' (Gillespie et al., 2012, p. 394). This is also the case in the UK, where currently more than one million people ( 2.2 per cent) are born of 'interracial' parentage (Census, 2011). Hence, what is the longevity of the current 'official' ethnic identity categories and consequently the research based on these categories? As all nebulous human categories become more and more blurred, to what extent will researchers remain capable of grouping respondents in categories based on ethnicity, nationality or religious affiliations?

\section{DISCUSSION: REACHING 'BEYOND IDENTITY'}

\section{'Beyond Identity' with Terminology}

Researchers need to reflect upon the terminology used in their research as to acknowledge which 'truth' and vision of reality they are contributing to with their results and conclusions. Further, clarifying these help the reader to reason what has actually been measured and from which angle the researchers have approached the data. Gillespie et al. (2012) remind all those who create or use social categories in order to sort people into cultural groups, to keep in mind that these categories are (1) perspectival, because the categories always stem from social position of the individuals creating these, their historical way of seeing, and their particular interests. Thus, there is no one way of assigning people into their 'true' categories. 'Immigrants were not immigrants before they left their home community. Equally, many do assimilate into the host culture and cease to think of themselves as immigrants' (Gillepsie et al., 2012, p. 395). Social categories are also (2) historical, because the way groups are conceptualized is changing and so are the groups themselves (Gillepsie et al., 2012, p. 394). As mentioned earlier, the fastest growing 'cultural groups' in the US and UK are those who self-identify themselves as 'mixed'. The global (3) movement of people also disrupts social categories: 'As selves move between social positions, roles, life stages, relationships, and countries and cultures, they accumulate increasingly diverse aspects of identities, which can interact in often surprising ways' (Gillepsie et al., 2012, p. 395).

In effect, Brubaker \& Cooper (2000, p. 34) suggest that it may not even be adequate to use the term identity for analytical purposes, as it is so 'riddled with ambiguity, riven with contradictory meanings, and encumbered by reifying connotations... multiple, fluid, constantly re-negotiated, and so on'. Nonetheless, as identity has carved its place in academic and mundane discourses, it cannot simply be discarded - novel ways to examine it are needed. To "unbundle the thick tangle of meanings that have accumulated around the term "identity", Brubaker and Cooper propose to reach 'beyond' the concept. They sketch three groups of terms, which permeate to approach identity from alternative angles. First, they suggest the term identification, which, unlike identity, is inherent to social life. In modern everyday settings and official contexts, there are multiple situations of interaction with others. These situations create numerous occasions for the individuals for identification, for characterizing oneself and for placing oneself in a category. Obviously, these identifications are deeply situational and contextual (Brubaker \& Cooper, 2000, p. 14). Identification is in harmony with the understanding of identity as a process - it behaves like a verb (Bauman, 1996) and translates as action - identification (Dervin, 2010).

Second, Brubaker and Cooper propose the term self-understanding, which refers to 'situated subjectivity'. This means one's sense of who one is and of one's social location and the understanding of how these two are related. Self-understanding may be variable or stable across time, but it is not connected with sameness or difference, unlike identity (Brubaker \& Cooper, 2000, p. 12). As a third 
substitute to the notion of identity, Brubaker and Cooper suggest the term groupness, the multiple forms of connectedness and commonality that describe a sense of belonging to a distinctive, bounded, solidary group (Brubaker \& Cooper, 2000, p. 20).

To give an empirical example of the use of these terms, let us observe how they were utilized in an on-going study as more precise constructs to explore the self-conceptions of internationally mobile youth and to analyze their narratives from a non-essentializing stance. Michael, one of the participants, is American-Canadian and with his family he has lived in several countries by the age of sixteen. Instead of simply categorizing him as a 'Third Culture Kid', which is a heavily loaded (and somewhat outdated) concept, the analysis disclosed several dimensions to Michael's selfimage. In terms of identification, Michael feels strong solidarity towards his family-he has been homeschooled for long and is proud of his family's 'strong morals' and the choices his parents have made. He also identifies with the Seventh-day Adventist community, of which his family is a member. Michael is aware that externally he is identified both as an American (abroad) and 'international' (in the US). As for groupness, Michael admits he has never really connected with anyone. He does not have many friends, but attributes a lot of meaning and significance to being a patriotic Republican. While waiting to join the US military troops after graduation, he finds feelings of commonality and groupness within the scouting movement. Finally, in terms of self-understanding, Michael is conscious of his biographical similarity to other mobile students in international schools, however, he feels inherently different from anyone he has ever met, mainly because of his family upbringing, their financial resources (status) and his personal interests.

As the example demonstrates, approaching identity through the use of research constructs such as identification, self-understanding and groupness enables the researcher to observe meaning making around 'self' from three different angles in order to draw a richer and a more complex portrait of the individual(s) in question.

\section{'Beyond' Identity by Combining Etic and Emic Approaches}

Now, with the more refined and representational concepts to work with, how can these areas then be observed from a methodological point of view? Dervin (2013: 24) argues that first and foremost one needs to move away from the idea of identity being an object towards the idea of identity being a process. That is, the only observable matter would be the process of identity construction. As process is always deeply embedded in the context, interaction and subjective interpretations of each individual, adopting a multi-method approach in the research framework would enable the researcher to observe the parameters from different angles.

It has become clear that scholars need to go below the surface of discourse in order to work towards more complex identification. If the individual is plural, complex, etc. repeating what she asserts as evidence is not enough. (Dervin 2013)

Instead of discussing whether knowledge is objective or subjective, Pike (1954) suggested considering different methodological solutions. He coined the terms etic referring to objective or outsider accounts, and emic referring to subjective or insider accounts (concepts were derived from an analogy with the terms 'phonemic' and 'phonetic'). Pike argued that combining these two might offer the 'richest' view of the researched phenomenon and to some extent compensate the weaknesses related to any single method and/or the researcher's position (Pike, 1954; see also Berry, 1989). Sixty years later, the concepts of etic and emic are still useful when linked to identity research. The term etic refers to a research approach aiming to work comparatively across 'cultures' and groups of people and in which the units and classifications are available in advance rather than determined during the analysis (cf. Brubaker \& Cooper's strong conception of identity). Etic approach assumes that these criteria may be considered absolute or measurable directly, and that the analyst may himself create the organization of a worldwide cross-cultural scheme (Pike, 1967, cited in Berry, 1989, p. 722). Emic 
approach, in turn, is more aligned with the current understandings of identity. It views the same people or phenomenon in the same context but from an 'insider's' perspective. Units or classifications are not pre-determined, but must be discovered. Emic research observes the ways individuals make meaning and act in their daily lives taking into account their attitudes, motives, interests and personality. It permits an understanding of the way the researched phenomenon is constructed (Berry, 1989, p. 723). However, researcher adopting an emic perspective should, as much as possible, reflect on his/her own preconceptions about the data and bracket this 'cultural baggage' with its theory-laden concepts, tools and knowledge in order to grasp the experiential world of the participant and to view identity in its full complexity (see also Smith et al., 2009 on Interpretative Phenomenological Analysis).

Ideally, in the data analyzing process, the researcher would move between the emic and etic perspectives. The etic perspective is reached when the data is interpreted with the application of concepts and theories that the researcher finds helpful to illuminate the understanding of the research topic (Pietkiewicz \& Smith, 2012, p. 4), while the participant-generated, emic perspective "protects researchers from psychological or psychiatric reductionism' (ibid). Combining the etic and emic accounts would result in a kind of 'tri-dimensional understanding of human behavior instead of a "flat" etic one' (Pike, 1967, cited in Berry, 1989, p. 724).

However, the transition between the two perspectives is not necessarily seamless. It is crucial for the researcher to provide a certain degree of transparency with a clear account of the analysis process so that the emic and etic will not amalgamate in the results-researcher's voice should be distinct from that of the participants (see also Kuusisto, 2011, p. 47). A great amount of transparency helps the researcher stay true to the original accounts and face possible ethical dilemmas arising from i.e. the participants' values or worldviews colliding with those of the researcher. This is relevant, because researchers are often torn between their efforts to understand (commitment to truth) and their desires to use their knowledge to change the world (commitment to personal values) (Vidich, 1988, p. 475). Hence, if researchers want to remain neutral and true to the participants' voices and the researched topic itself, they need to stay 'open to all the relevant data, and [have] a willingness to accept findings that do not conform to expectations, values, ethics, or politics. Ethical and political neutrality are then coincident with the search for truth' (Vidich, 1988, p. 485).

Nevertheless, it is essential to recall that all descriptions and the theories elaborated always reflect the historical period of their formulation and disclose what the authors (researchers) consider salient for investigation at that particular time (Vidich, 1991). Further, as Friedman (1992) puts it, the 'world is already defined' and research - emic and etic - is conducted therein. No pristine interpretation exist, researchers and participants can only refer to something that already exists in the world (Kincheloe, 2002, p. 97). But it is exactly here where adopting an emic stance becomes salient; whereas purely etic identity research is limited to operating within the existing social categories, emic approach gives space for individual interpretation and allows discovering novel self-descriptions created by the actors themselves. Researcher's commitment to the lived experiences and sense-making of the participants enables deconstructing some outdated, clear-cut categories (i.e. Third Culture Kid, Straight-Gay) and reaching towards category-less-ness representations of the accounts.

\section{CONCLUSION}

I tell you everything that is really nothing, and nothing of what is everything, do not be fooled by what I am saying. Please listen carefully and try to hear what I am not saying. (Finn, 1966)

There is inconsistency between the current understanding of the nature of identity and the classic social categories framing identities based on features like ethnicity, race, nationality or religion. Traditional identity categories and measures echo the period of strong identity conceptions that emphasize sameness across persons and over time. However, as many societies have undergone major 
cultural and demographic changes in a relatively short time and as the awareness of the diversity of identities has increased, the understanding of the nature of identity has dramatically changed, too. The post-modern understanding of identity characterizes it as unique, shifting and context-specific. In this light, identity measures operating solely with pre-selected categories and objective descriptions no longer project the phenomena they were designed for, especially when only one survey or questionnaire is being used. Information obtained from these studies may help in understanding the world and social realities around us, but the problem is that the identities these studies bring forth are seen as coherent and uniform and as if shared by all members of the given category. As such, they fail to reflect the diversifying demographic of the societies today and especially the multidimensional lifeworlds of the contemporary children and youth. Not only do identity categories leave little space for the individual to define her/himself, but as individuals are constantly moving through and between roles, stages, groups and belongings, the distinctive descriptions of group or individual categories always seem to be out of date and somehow stuck in the past (i.e. Hofstede \& Hofstede, 2005).

Even though there is a counter movement in some parts of the world to strengthen religious, national and/or ethnic categorization, in many contexts (especially related to the youth) these boundaries are becoming more and more porous. Therefore, it is not meaningful for research to further strengthen the traditional, etic social categories as this may contribute to creating 'neo-culturalism/neoessentialism' (Dervin, 2010, p. 6). To avoid this, researchers and authorities need to move away from a language that speaks of outdated nation-bound ideologies and worldviews, which often surface as consequences of incidents involving a presumed 'threat' to a nation, people or religion. Unfortunately, instead of speaking of distinct individuals or groups, public discourses often tag the 'threats' with a religion or ethnicity. These types of essentializing debates have followed, for example, the ' $9 / 11$ ' in the US, the 2005 bombings in London (as referred to earlier, Sen, 2009), and more recently after the Charlie Hebdo episode in Paris 2015. In these discourses the malefactors' motivations are sometimes explicated by the values and worldviews of their respective social categories (i.e. religion or ethnicity), which, in consequence, intensifies the stereotypes, othering and thus incoherence in the societies.

In order to avoid these kinds of hazardous amalgams and to understand the self-conceptions of the contemporary individuals, one has to look beyond imposed or adopted 'identities' in search of richer, more complex and subjective statements of individuality. What research should be looking after are expressions of identifications, self-understandings and senses of groupness of the participants that better illuminate the complex, changing nature of the self than any given identity category. Etic identity research should be complemented by emic approaches that empower the participants and enable them to tell the story of the self in their own voice, terms and criteria. First and foremost researchers and practitioners should approach identity as a process, respecting the individual right to self-categorization and membership negotiation. Research has always adapted to changes in society adopting new, appropriate methodologies (Groves, 2011). It is time view identity research in a broader light considering its impact on each level of the society. 


\section{REFERENCES}

Abdallah-Pretceille, M. (2006). Interculturalism as a paradigm for thinking about diversity. Intercultural Education, 17(5), 475-483. doi:10.1080/14675980601065764

Adichie, C. N. (2009). The danger of a single story. TED-talk, TEDGlobal 2009. Retrieved from http://www. ted.com/talks/chimamanda_adichie_the_danger_of_a_single_story.html

Anglin, A. E., Johnson-Pynn, J. S., \& Johnson, L. R. (2012). Ethnic identity and civic attitudes in Latino and Caucasian youth. Journal of Youth Studies, 15(5), 621-643. doi:10.1080/13676261.2012.663887

Appiah, K. A. (2005). The ethics of identity. Princeton University Press.

Ariel de Vidas, A., \& Hoffmann, O. (2011). Beyond reified categories: Multidimensional identifications among 'black' and 'Indian' groups in Columbia and Mexico. Ethnic and Racial Studies, 35(9), 1596-1614. doi:10.10 80/01419870.2011.594176

Bauer, S., Loomis, C., \& Akkari, A. (2013). Intercultural immigrant youth identities in contexts of family, friends, and school. Journal of Youth Studies, 16(1), 54-69. doi:10.1080/13676261.2012.693593

Bauman, Z. (1996). From pilgrim to tourist: Or a short history of identity. In S. Hall \& P. du Gay (Eds.), Questions of cultural identity (pp. 18-36). London, UK: Sage.

Benjamin, S., \& Dervin, F. (2015). Migration, diversity and education: Beyond Third Culture kids. London, UK: Palgrave Macmillan. doi:10.1057/9781137524669

Berry, J. W. (1989). Imposed etics-emics-derived etics: The operationalization of a compelling idea. International Journal of Psychology, 24(2-6), 721-735. doi:10.1080/00207598908247841

Brubaker, R. (2013). Categories of analysis and categories of practice: A note on the study of Muslims in European countries of immigration. Ethnic and Racial Studies, 36(1), 1-8. doi:10.1080/01419870.2012.729674

Brubaker, R., \& Cooper,F.(2000). Beyond “identity”. Theoryand Society, 29(1), 1-47.doi:10.1023/A:1007068714468

Burlew, A. K., Bellow, S., \& Lovett, M. (2000). Racial identity measures: A review and classification system. In R. Dana (Ed.), Handbook of cross-cultural and multicultural personality assessment (pp. 173-196). Mahwah, NJ: Lawrence Erlbaum Associates Publishers.

Cetrez, O. (2011). The next generation of Assyrians in Sweden: Religiosity as a functioning system of meaning within the process of acculturation. Mental Health, Religion \& Culture, 14(5), 473-487. doi:10.1080/136746 76.2010 .484061

Deaux, K., \& Martin, D. (2003). Social categories: Specifying levels of context in identity processes. Social Psychology Quarterly, 66(2), 101-117. doi:10.2307/1519842

Dervin, F. (2010). Researching identity and interculturality: From methodological nationalism, via transnationalism, to mixed intersubjectivity. Paper presented at Malaysia International Conference on Foreign Languages, Kuala Lumpur, Malaysia.

Dervin, F. (2011). Cultural identity, representation and Othering. In Jackson, J. (dir.). Routledge handbook of intercultural communication (pp. 181-194). London, UK: Routledge.

Dervin, F. (2013). Researching identity and interculturality: Moving away from methodological nationalism for good? In R. Machart, C. B. Lim, S. N. Lim, \& E. Yamato (Eds.), Intersecting identities and interculturality: Discourse and practice (pp. 1-29). Newcastle upon Tyne: Cambridge Scholars Publishing.

Finn, C. C. (1966/2011). Please hear what I'm not saying. A poem's reach around the world. Bloomington: AuthorHouse.

Friedman, J. (1992). The past in the future. History and the politics of identity. American Anthropologist, 94(4), 837-859. doi:10.1525/aa.1992.94.4.02a00040 
Gillespie, A., Howarth, C. S., \& Cornish, F. (2012). Four problems for researchers using social categories. Culture and Psychology, 18(3), 391-402. doi:10.1177/1354067X12446236

Groves, R. M. (2011). Three eras of survey research. Public Opinion Quarterly, 75(5), 861-871. doi:10.1093/ poq/nfr057

Helve, H. (2015). Re-thinking youth and citizenship. Value groups and citizen types of young Finns. Italian Journal of Sociology of Education, 7(1), 32-66.

Hofstede, G., \& Hofstede, G. J. (2005). Cultures and organizations. Software of the mind. New York, NY: McGraw-Hill.

Insee (2012). La Situation Demographique en 2012. Institut national de la statistique et des études économiques. Retrieved from http://www.insee.fr/fr/default.asp

Juang, L., \& Syed, M. (2010). Family cultural socialization practices and ethnic identity in college-going emerging adults. Journal of Adolescence, 33(3), 347-354. doi:10.1016/j.adolescence.2009.11.008 PMID:20022364

Kincheloe, J. L., \& McLaren, P. (2002). Rethinking Critical Theory and Qualitative Research. In Y. Zou, \& E. Trueba (Eds.), Ethnography and schools: Qualitative approaches to the study of education (pp. 87-138). Rowman \& Littlefield Publishers.

Krumer-Nevo, M., \& Sidi, M. (2012). Writing against othering. Qualitative Inquiry, 18(4), 299-309. doi: $10.1177 / 1077800411433546$

Kuusisto, A. (2005). Methodological issues and challenges in studying young people's religious identity. In H. Helve (Ed.), Mixed methods in youth research (pp. 197-212). Helsinki, Finland: Finnish Youth Research Network.

Kuusisto, A. (2011). Growing up in affiliation with a religious community. A case study of seventh-day adventist youth in Finland. Munster: Waxmann.

Lagström, H., Pösö, T., Rutanen, N. \& Vehkalahti, K. (toim.) (2010). Lasten ja nuorten tutkimuksen etiikka. Nuoristotutkimusverkosto/Nuorisotutkimusseura. Julkaisuja 101.

Lentin, A. (2014). Post-race, post politics: The paradoxical rise of culture after multiculturalism. Ethnic and Racial Studies, 37(8), 1268-1285. doi:10.1080/01419870.2012.664278

McCabe, S. E., Hughes, T. L., Bostwick, W., Morales, M., \& Boyd, C. J. (2012). Measurement of sexual identity in surveys: Implications for substance abuse research. Archives of Sexual Behavior, 41(3), 649-657. doi:10.1007/ s10508-011-9768-7 PMID:21573706

Monrad, M. (2013). On a scale of one to five, who are you? Mixed methods in identity research. Acta Sociologica, 56(4), 347-360. doi:10.1177/0001699313481368

Ogan, C., Karakuş, T., \& Kurşun, E. (2013). Methodological issues in a survey of children's online risk-taking and other behaviours in Europe. Journal of Children and Media, 7(1), 133-150. doi:10.1080/17482798.2012.739812

Otcu, B. (2010). Heritage language maintenance and cultural identity formation: The case of a Turkish Saturday school in New York City. Heritage Language Journal, 7(2), 112-137.

Pearson, J. A., \& Geronimo, A. (2011). Race/ethnicity, socioeconomic characteristics, coethnic social ties, and health: Evidence from the National Jewish Population Survey. American Journal of Public Health, 101(7), 1314-1321. doi:10.2105/AJPH.2009.190462 PMID:21164093

Phinney, J. S. (1992). The multigroup ethnic identity measure: A new scale for use with diverse groups. Journal of Adolescent Research, 7(2), 156-176. doi:10.1177/074355489272003

Pietkiewicz, I., \& Smith, J. A. (2012). Praktycny przewodnik interpretacyjnej analizy fenomenologicznej w badaniach jakosciowych w psychologii. Czasopismo Psychologiczne, 18(2), 361-369.

Pike, K. L. (1954). Language in relation to a unified theory of the structure of human behavior. The Hague: Mouton.

Prentice, D. A., \& Miller, D. T. (2007). Psychological essentialism of human categories. Current Directions in Psychological Science, 16(4), 202-206. doi:10.1111/j.1467-8721.2007.00504.x 
Puuronen, V. (2005). Methodological starting points and problems of youth research. In H. Helve (Ed.), Mixed methods in youth research (pp. 15-28). Helsinki: Finnish Youth Research Network.

Rantala, T., \& Kuusisto, A. (2013). Examining researcher's position through its interaction with methodological and ethical particularities of religion and gender. In K. Tirri \& E. Kuusisto (Eds.), Interaction in educational domains (pp. 63-73). Rotterdam: Sense Publishers. doi:10.1007/978-94-6209-395-9_6

Sellers, R. M., Smith, M. A., Shelton, J. N., Rowley, S. A. J., \& Chavous, T. M. (1998). Multidimensional model of racial identity: A reconceptualization of African American racial identity. Personality and Social Psychology Review, 2(1), 18-39. doi:10.1207/s15327957pspr0201_2 PMID:15647149

Sen, A. (2009). The fog of identity. Politics, Philosophy \& Economics, 8(3), 285-288. doi:10.1177/1470594X09105388

Shabes, V., Bostedt, G., Troshchenkova, E., Ivarsson, L., Lamber, U., \& Potapova, T. (2011). An experimental study of Russian and Swedish value systems. Paper presented at the 4th Global Conference on Interculturalism, Meaning and Identity, Prague, Czech Republic.

Smith, J. A., Flowers, P., \& Larkin, M. (2009). Interpretative phenomenological analysis. Theory, method and research. London, UK: Sage.

Starr, P. (1992). Social categories and claims in the liberal state. Social Research, 59(2), 263-295.

Stevens, P. A. J. (2007). Researching race/ethnicity and educational inequality in English secondary schools: A critical review of the research literature between 1980 and 2005. Review of Educational Research, 77(2), 147-185. doi:10.3102/003465430301671

Tajfel, H. (1981). Human groups \& social categories. Studies in Social Psychology. New York, NY: Cambridge University Press.

Tajfel, H., \& Turner, J. C. (1979). An integrated theory of intergroup conflict. In W. G. Austin, W., G. \& Worchel, S. (Eds.). The social psychology of intergroup relations. Monterey, CA: Brooks-Cole.

Thomson, P. (Ed.), (2008). Doing visual research with children and young people. Oxon, MD: Routledge.

UK Office for National Statistics. (2011). Census. Retrieved from http://www.ons.gov.uk/ons/taxonomy/index. html?nscl=People+and+Places

UN. (2013). United Nations Department of Economic and Social Affaires. Retrieved from http://www.un.org/ en/development/desa/news/population/number-of-international-migrants-rises.html

Vasey, P. L., Parker, J. L., \& VanderLaan, D. P. (2014). Comparative reproductive output of androphilic and gynephilic males in Samoa. Archives of Sexual Behavior, 43(2), 363-367. doi:10.1007/s10508-013-0195-9 PMID:24132776

Verkuyten, M., Thijs, J., \& Stevens, G. (2012). Multiple identities and religious transmission: A study among Moroccan-Dutch Muslim adolescents and their parents. Child Development, 83(5), 1577-1590. doi:10.1111/ j.1467-8624.2012.01794.x PMID:22966924

Vidich, A. J. (1988). The values and morality of scientists: Some unresolved problems. International Journal of Politics Culture and Society, 1(3), 471-486. doi:10.1007/BF01385431

Vidich, A. J. (1991). Social theory and the substantive problems of sociology. International Journal of Politics Culture and Society, 4(4), 517-534. doi:10.1007/BF01390156

Waterman, S. (2015). Press article. U.S. officials urged to avoid linking Islam, jihad with terrorism. Retrieved from http://www.upi.com/Emerging_Threats/2008/05/06/US-officials-urged-to-avoid-linking-Islam-jihad-with-te rrorism/93701210085457/\#ixzz3UvIw7exN

Whitehead, K. A., Ainsworth, A. T., Wittig, M. A., \& Gadino, B. (2009). Implications of ethnic identity exploration and ethnic identity affirmation and belonging for intergroup attitudes among adolescents. Journal of Research on Adolescence, 19(1), 123-135. doi:10.1111/j.1532-7795.2009.00585.x PMID:19756207

Wiley, S., Philogene, G., \& Revenson, T. A. (Eds.). (2012). Social categories in everyday experiences. Magination Press. American Psychological Association. doi:10.1037/13488-000 
Saija Benjamin (M.Ed.) is doctoral researcher at the Department of Teacher Education, University of Helsinki, Finland. In her PhD research she investigates adolescents' meaning making and experiences of multi-mobility.

Arniika Kuusisto (PhD, M.Ed.) is Adjunct Professor and University Lecturer in Education at the Department of Teacher Education, University of Helsinki, Finland. Her research interests include children's and young people's negotiations on values and memberships in their everyday settings. 